\title{
The Royal Society of Medicine
}

It is nearly 25 years since the Platt Report (Standing Medical Advisory Committee, 1962) stated that accident and emergency work is 'unlikely to provide a satisfactory career for a consultant' and recommended that the departments should be managed by a consortium of consultants with an orthopaedic consultant in day-to-day administrative charge.

Those past 25 years have seen the establishment, development and flowering of a new, dynamic specialty of accident and emergency medicine led by a consultant body who can afford to smile at these 'famous last words.' There is no better occasion for joy and pride in our achievements than the recognition of our specialty by the Royal Society of Medicine. We were granted a specialty section, the thirty-fourth of the Society, and our inaugural meeting, followed by the inaugural symposium on Medico-Legal Aspects of Accident and Emergency Medicine, took place on the 19 January 1987.

According to Sir John Walton, the Royal Society of Medicine is the 'nearest thing we have in Britain to a national academy of medicine.' The Society is not a political organisation, but it has considerable influence on medical information on education at home and abroad. It provides a forum for all scientific and academic endeavours relevant to the specialist sections and, through its open section, to the broader medical issues of public interest. The Society promotes links with the national and international specialty sections in North America, the Commonwealth and Europe. It organises scientific meetings, houses one of the most comprehensive medical libraries in the world, and engages in a range of audiovisual and publishing activities. The recently opened headquarters provide splendid club, hotel and restaurant facilities.

The new section of Accident and Emergency Medicine will offer all these opportunities and facilities to its membership. In 1987, we shall organise three symposia on 'burning issues' and we are planning to start clinical meetings, often jointly with related specialties, in 1988.

We hope to recruit fellows and associate fellows who will be involved in the running and developing of the section, but those who do not become fellows are also welcome to attend meetings and to bring their nursing and medical staff with them.

We are entering a new and exciting area; it is both a journey and a destination, and we can make it a success with the enthusiastic support of our colleagues in accident and emergency medicine.

\section{REFERENCE}

Standing Medical Advisory Committee (Chairman: Sir Harry Platt) (1962) Accident and Emergency Services. Her Majesty's Stationary Office, London.

V. DALLOS

President, Section of Accident and Emergency Medicine, Royal Society of Medicine 